\title{
Microneedle Array: Applications, Recent Advances, and Clinical Pertinence in Transdermal Drug Delivery
}

\author{
Jitu Halder ${ }^{1}$. Sudhanshu Gupta ${ }^{1}$. Rakhi Kumari ${ }^{1}$ - Ghanshyam Das Gupta ${ }^{1}$ - Vineet Kumar Rai ${ }^{1}$ (I)
}

Published online: 8 June 2020

(C) Springer Science+Business Media, LLC, part of Springer Nature 2020

\begin{abstract}
Drug delivery through the skin by transdermal patches has a long history. Subsequent growth of transdermal science proved prominent utility of transdermal systems meant for passive diffusion of the drug. It was followed by the development of iontophoresis- and sonophoresis-based transdermal delivery systems. Microneedle array has now caught attention of the investigators owing to its immense utility in transdermal delivery of very large molecules with ionic and hydrophilic nature. In this technical note, we present the current scenario, applications, and recent advances in microneedle array-based delivery of the most critical molecules through the skin. The application of microneedle has widely been investigated, and these technologies are being developed for the delivery of bio-therapeutics, bio-macromolecules, insulin, growth hormones, immunobiologicals, proteins, siRNA, and peptides. Potential of microneedles to transform the global transdermal market is highlighted in terms of the success rate of the microneedle technologies in clinical trials reaching to the global market. The arrival of the commercial microneedle-based products in the market is highly anticipated as they have potential to portray remarkable impact on clinical medicine in near future.
\end{abstract}

Keywords Microneedle $\cdot$ Transdermal $\cdot$ Vaccines $\cdot$ Drug delivery $\cdot$ Protein and peptides

\section{Introduction}

The transdermal route, in many clinical implications, is used to avoid the decisive limitations associated with the oral drug delivery methods [1]. The recent developments in this area highlight the utility of microneedle array (MN) systems in delivering drugs transdermally that are unable to diffuse through skin by passive diffusion or by external source-assisted diffusion [2]. MN has been proved as a convenient technique in delivering molecules of high molecular mass. Moreover, it is designed to keep one away from the pain-related issues while being injected with the hypodermic needles [3]. Here, we present the current scenario, the applications, and the recent advances in the delivery of molecules by microneedle array technique. Various ways have been explored to deal with the limited potency of a therapeutic agent. Consequently, future research will concentrate on creating techniques to diminish loss during preparing and stacking just as

Vineet Kumar Rai

raivk.gkp@gmail.com

1 Department of Pharmaceutics, ISF College of Pharmacy, Moga, Punjab 142001, India improving the structures of microneedles to guarantee better medication transport to make microneedle-based treatment more affordable, especially for developing countries. Though the investigations on microneedle-based drug delivery systems are expanding every year, the shortcomings associated with these systems should carefully be addressed. This would let microneedles pass the clinical pertinence and help reach to the potential market. Some of the microneedle-based drug delivery systems have entered in phase III clinical trials. However, the clinical pertinence of microneedle in vaccination is yet to be proved $[4,5]$. Therefore, efforts that are being made to deliver the drug by microneedle array technique have placed them to the next level and eventually become recognized as a strong alternative to the hypodermic needles. This review highlights the applications, recent advances, and clinical pertinence of these systems in transdermal delivery of the drugs for potential therapeutic and safety benefits.

\section{Transdermal Drug Delivery and Beyond}

The global drug delivery market has been observed as large as 440.5 billion USD in 2018. Considering cost-effectiveness, 
bioavailability, and quick action, injectables are known to be very efficient. These systems have immensely been used in the delivery of biological macromolecules, insulin, vaccines, and dots. However, their invasive nature, stability issues, and noncompliance have always been the issues of concern and led to the requirement of highly skilled medical practitioners for administration [6]. Some of the measures have been taken into consideration to replace all such needles; however, necessary improvement could not be made. The history of conventional transdermal drug delivery systems is almost five decades old. Several drugs, viz. testosterone, nicotine, selegiline, and clonidine, have been delivered successfully by these systems. These types of drug delivery systems proved to be a patient-friendly, effective, and painless techniques. However, the longer onset of action, restriction of delivering only molecules of smaller molecular weight and lipophilicity limited their utility in the delivery of most of the critical macromolecules. Penetration enhancers, iontophoresis, and sonophoresis techniques could solve the purpose up to some extent, but efficient delivery of the drugs in compliance with the patients was a major concern. The application of microneedle has now been widely investigated, and these technologies are being developed specifically for the delivery of biological macromolecules, insulin, growth hormones, immunobiological, proteins, siRNA, and peptides [7]. When studied in terms of the success rate of the microneedle technologies in clinical trials reaching the global market, these have been found to show immense potential to transform the global transdermal market.

\section{Micro-Needle Patches}

The micro-needles are so tiny to see from the naked eye, in fact, less than one millimeter in height [8]. This micron-sized needle punctures the stratum corneum (the layer of skin that provides the larger barrier for the diffusion of the actives) and creates the pathway that allows the drug molecule to diffuse

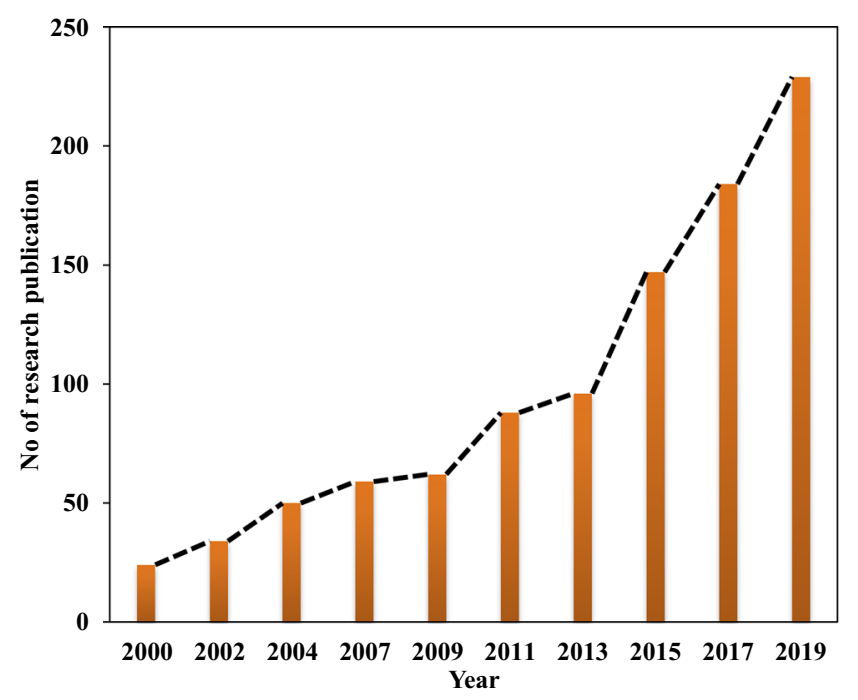

Fig. 1 Year wise (from 2000 to 2019) trend in MN array-based research

directly beneath the skin much more quickly. MN was firstly conceptualized in 1970s by Martin S. Gerstel and Virgil A. Place [9]. The report was published in the late 90s [10] where it was used as a drug delivery device for percutaneous administeration of a drug directly to the dermis layer and to produce a local and systemic pharmacological effect. In addition to its painless behavior, it has been used to improve the bioavailability of proteinaceous drugs [11]. MNs have made the delivery of even very complex molecules, like protein, vaccines, and peptides, possible through the transdermal route. Microneedle can be of different types, such as solid, hollow, coated, and dissolving; however, all types of MNs are ultimately used to achieve fast and efficient drug delivery [12]. In every type of microneedles, needle length is to be adjusted appropriate enough to penetrate the SC and not to puncture nerve endings. If it does not puncture a nerve ending, no pain will be observed at the site. Additionally, these systems have the ability to control the release of the drug and provide safe administration as compared to that of the surgical implantation [13]. However, it has some disadvantages like the requirement of the sophisticated fabrication process in
Table 1 List of ingredients used for the preparation of microneedle

\begin{tabular}{llll}
\hline Metals & Biodegradable polymers & Non-biodegradable polymers & Natural polymers \\
\hline Sillicon & PLGA & Alginic acid & Zein \\
Titanium & PLA & Gantrez AN-139 & Chitosan \\
Stainless steel & PVP & Polyvinyl acetate & Thermoplastic starch \\
Silicon & Polyglycolic acid & Polyvinyl alcohol (PVA) & Carboxymethyl cellulose \\
Palladium & Polycarbonate & Carbopol 971 P-NF & Amylopectine \\
& Polyvinylpyrrolidone & Polyetherimide & Dextran \\
& & & Galactose \\
& & & Maltose \\
& & & Chondroitin sulfate \\
\hline
\end{tabular}


Fig. 2 Applications of microneedle array in transdermal drug delivery

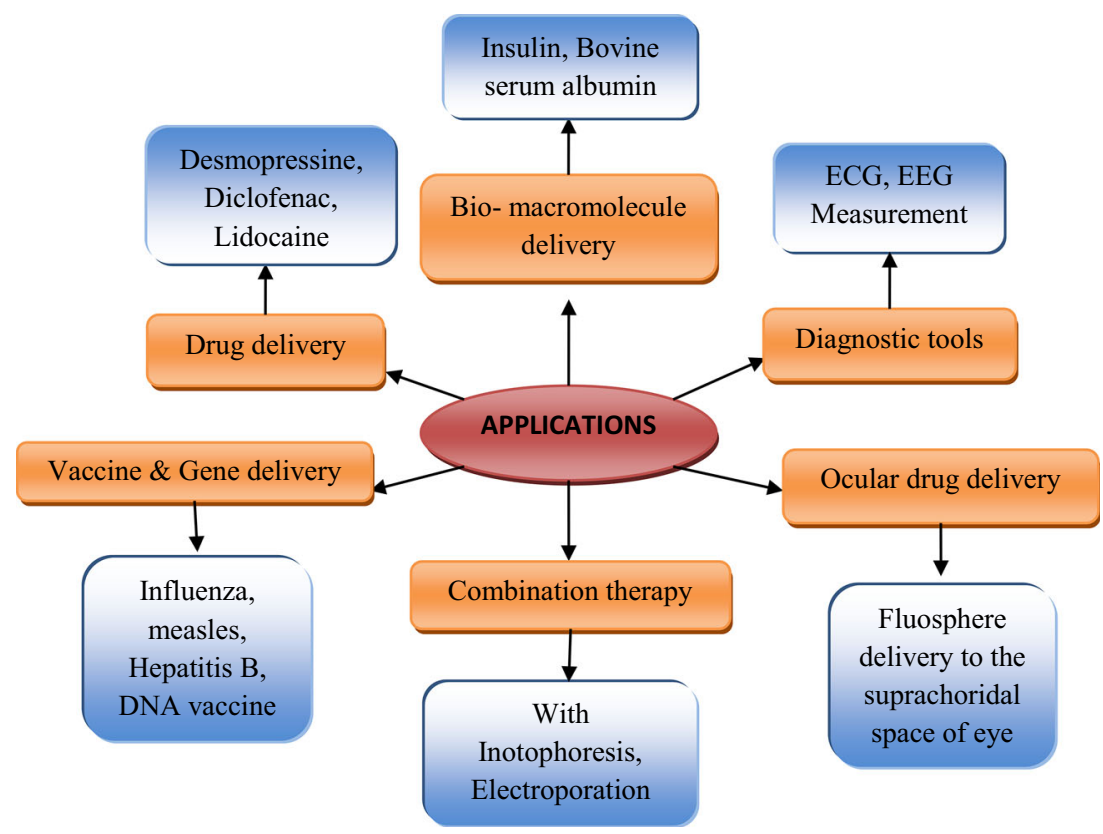

which preparation of primary mold is required for the development of the MN patch. Mold is normally prepared with the help of polydimethylsiloxane (PDMS) and resins $[14,15]$. If the silicon present in PDMS is left with the needle, it may create skin problems, such as skin irritation and local inflammation. Also, the cost of this technology could be high [16] and the dose accuracy may be less as compared to that of the hypodermic needles. Preferably, very less amount of drugs can be loaded into or coated over the microneedle tips; therefore, drugs with a low dose (few milligram per kilogram body weight) are preferred. MN should be used carefully to avoid particles "bouncing off" the skin surface. In the case when the device is not held vertically, the dose may escape or can penetrate the skin to differing degrees [17].

\section{Ideal Characteristics of Microneedle Patch}

The length or height range of microneedle is varied between 50 to $900 \mu \mathrm{m}$ and $1 \mu \mathrm{m}$ in diameter [8, 13]. The developed MNs must be capable of deep insertion into the skin without breaking. MNs should have an optimum size. These must be able to withstand the insertion force about $10 \mathrm{~N}$ and should have proper mechanical stability [18]. These are also developed for controlled delivery of the drugs with a predetermined rate. These should be able to provide a quick onset of action and efficient drug delivery much like a hypodermic needle. These are developed to enhance self-medication and facilitate personalized medication at different dose levels [19]. The durability of these products needs to be more, and these should be leak-proof while delivering drugs of a liquid state. Adherence of these patches needs to be good or as similar to regular transdermal patches.

\section{Polymer Used in Microneedle Formulation}

In microneedle manufacturing, the major factor that is considered is the strength of the needle because microneedle must get inserted into the epidermal layer without breaking for proper delivery of the drug [18]. The size and shape of microneedles are also essential, along with the sharpness of the tip of the needle. In addition, the biocompatibility of the needles with the biosystem is also very critical [20]. Therefore, polymer selection for the development of microneedles is very crucial. The ideal polymer should be biocompatible and must be able to provide sufficient mechanical strength to the microneedles [21]. Ingredients used for the preparation of microneedles include glass, silicone, and metals, such as stainless steel, titanium, solid or coat of gold over nickel, palladium, cobalt, platinum, synthetic, and natural polymers. Some of the materials that have been used and reported for the development of microneedles are listed in Table 1.

\section{Applications of Microneedle Array Technique in Transdermal Drug Delivery}

The development of a microneedle array has gained momentum and now become the area of prime research. As much as 2569 research papers have been retrieved until now (from 2000 to 2019) from PubMed using the search term "microneedle." Other databases, like Scopus and Google Scholar, have also been used for the same. Year-wise trends in microneedle development for drug delivery can be seen in Fig. 1. Single entry was made for one research work. 
Table 2 Status of clinical trials based on MN technique

\begin{tabular}{|c|c|c|c|c|c|}
\hline NCT No. & Condition & Drug & Phase & Location & Status \\
\hline NCT00837512 & Type 1 DM & Insulin & $\begin{array}{l}2 \\
3\end{array}$ & $\begin{array}{l}\text { Eric Felner, MD, MSCR, Emory } \\
\text { University }\end{array}$ & Completed \\
\hline NCT03054480 & Primary axillary hyperhidrosis & Botulinum toxin type A & NA & $\begin{array}{l}\text { Thep Chalermchai, Mae Fah Luang, } \\
\text { University Hospital }\end{array}$ & Completed \\
\hline NCT03607903 & Pain & $\begin{array}{l}\text { Adalimumab ID, } \\
\text { Adalimumab SC }\end{array}$ & $\begin{array}{l}1 \\
2\end{array}$ & $\begin{array}{l}\text { Centre for Human Drug Research, } \\
\text { Netherlands }\end{array}$ & Active \\
\hline NCT01812837 & Actinic keratosis & Aminolevulinic acid & NA & University of California, Davis & Completed \\
\hline NCT03203174 & Hyperhidrosis & Botulinum toxin type A & 1 & University of California, Davis & Completed \\
\hline NCT01789320 & $\begin{array}{l}\text { Uveitis, intermediate uveitis, } \\
\text { posterior uveitis, panuveitis, } \\
\text { noninfectious uveitis }\end{array}$ & $\begin{array}{l}\text { Triamcinolone acetonide } \\
\quad \text { (Triesence } 囚)\end{array}$ & $\begin{array}{l}1 \\
2\end{array}$ & Clearside Biomedical, Inc. & Completed \\
\hline NCT02594644 & Keratosis, actinic & Aminolevulinic acid & NA & University of California, Davis & Completed \\
\hline NCT02632110 & Actinic keratosis & Topical solution vehicle & 2 & DUSA Pharmaceuticals, Inc. & Completed \\
\hline NCT02438423 & Influenza & $\begin{array}{l}\text { Inactivated influenza } \\
\text { vaccine }\end{array}$ & 1 & $\begin{array}{l}\text { Mark Prausnitz, Georgia Institute of } \\
\text { Technology }\end{array}$ & Completed \\
\hline NCT02745392 & Acute migraine & $\begin{array}{l}\text { ZP Zolmitriptan } \\
\text { Placebo }\end{array}$ & $\begin{array}{l}2 \\
3\end{array}$ & Zosano Pharma Corporation & Completed \\
\hline NCT03646188 & Basal cell carcinoma & $\begin{array}{l}\text { Doxorubicin-containing } \\
\text { MNA }\end{array}$ & 1 & SkinJect, Inc. & Recruiting \\
\hline NCT01049490 & Influenza infection & S-OIV H1N1 vaccine & NA & $\begin{array}{l}\text { Dr. Ivan FN Hung, The University of } \\
\text { Hong Kong }\end{array}$ & Completed \\
\hline NCT03847610 & Healthy volunteers & Phenoxymethyl penicillin & 1 & Imperial College London & Completed \\
\hline NCT02192021 & Cutaneous $\mathrm{T}$ cell lymphoma & Doxorubicin (MNA-D) & 1 & $\begin{array}{l}\text { Oleg E. Akilov, MD, PhD, University } \\
\text { of Pittsburgh }\end{array}$ & Recruiting \\
\hline NCT01304563 & Influenza & $\begin{array}{l}\text { TIV 2010/2011 influenza } \\
\text { vaccine }\end{array}$ & NA & The University of Hong Kong & Completed \\
\hline NCT02837094 & Type 1 diabetes & C19-A3 GNP & 1 & Cardiff University & $\begin{array}{l}\text { Active, not } \\
\text { recruiting }\end{array}$ \\
\hline NCT00558649 & Influenza, human & Flu vaccine (FLUARIX®) & NA & NanoPass Technologies Ltd & Completed \\
\hline NCT03126786 & Diabetic macular edema & $\begin{array}{l}\text { IVT aflibercept, Sham SC, } \\
\text { SC CLS-TA }\end{array}$ & 2 & Clearside Biomedical, Inc. & Completed \\
\hline NCT03097315 & $\begin{array}{l}\text { Uveitis, posterior uveitis, anterior uveitis, } \\
\text { intermediate panuveitis }\end{array}$ & CLS-TA & 3 & Clearside Biomedical, Inc. & Completed \\
\hline NCT04053140 & Healthy volunteers & Penicillin G & 1 & Imperial College London & Recruiting \\
\hline
\end{tabular}

Conference proceedings were excluded. These technologies are being developed for delivering biotherapeutics, biomacromolecules, like insulin, growth hormones, immunobiological, proteins, and peptides. Insulin-loaded dissolvable microneedle of starch and gelatin and bovine serum albumin microneedles are some of the very explicit examples [22]. Vaccine delivery by the microneedle technology is meant to replace hypodermic needle for avoiding sitespecific pain. Kommareddy et al. investigated influenza subunit vaccine-coated microneedle patches for their elicit comparable immune responses with intramuscular injections in guinea pigs [23]. A very new investigation made recently by Kim et al. [24] reports the recombinant coronavirus vaccine delivery through skin with the help of microneedle technology for the treatment of COVID-19. This technology helped deliver SARS-CoV-2 S1 subunit vaccines that elicited potent antigen-specific antibody responses that were evident beginning 2 weeks after immunization, and their studies supported the clinical development of MN-based recombinant protein subunit vaccines against SARS, MERS, COVID-19, and other emerging infectious diseases [24]. For ocular drug delivery, the microneedle-based approaches have been observed to be more effective than topical application. Patel et al. successfully tested suprachoroidal drug delivery to the back of the eye using hollow microneedle [25]. Microneedle has also been used for local anesthesia. In an investigation, Baek et al. [26] suggested the use of microneedles in pain-free and rapid local anesthesia. They developed lidocaine coated microneedle that showed in vitro skin penetration and enhanced delivery of the drug in a very short duration, i.e., in 2 min [26]. For pain management, meloxicam-loaded polymeric microneedles have also been prepared using polydimethylsiloxane molds. The in vitro release studies showed approximately $100 \%$ drug release in $60 \mathrm{~min}$. The drug 
Table 3 Marketed microneedle-based transdermal products

\begin{tabular}{|c|c|c|c|}
\hline Brand name & Manufacturer & Description & Application \\
\hline Darmaroller® & Derma spark, Canada & $\begin{array}{l}\text { Metallic microneedle } \\
\text { array }\end{array}$ & $\begin{array}{l}\text { Used to treat acne, stretch mark, hair loss. Able to enhance drug absorption } \\
\text { (minoxidil, hyaluronic acid, etc.). }\end{array}$ \\
\hline MicroHyala® & $\begin{array}{l}\text { CosMED } \\
\text { Pharmaceutical Co. } \\
\text { Ltd., Japan }\end{array}$ & $\begin{array}{l}\text { Dissolvable } \\
\text { microneedle patch }\end{array}$ & It contains hyaluronic acid that is released in the skin to treat wrinkle. \\
\hline VaxMat ${ }^{\circledR}$ & TheraJect Inc., USA & $\begin{array}{l}\text { Dissolvable } \\
\text { microneedle patch }\end{array}$ & It is used to deliver macromolecules, like proteins, peptides, and vaccines. \\
\hline Micro-Trans $®$ & Valeritas Inc., USA & Microneedle patch & $\begin{array}{l}\text { It delivers the drug into the dermis without limitations of drug size, structure, } \\
\text { charge, or the patient's skin characteristics. }\end{array}$ \\
\hline Drugmat $\AA$ & TheraJect Inc., USA & $\begin{array}{l}\text { Dissolvable } \\
\text { microneedle patch }\end{array}$ & $\begin{array}{l}\text { It delivers hundreds of micrograms of drug rapidly through the stratum } \\
\text { corneum into the epidermal tissue. }\end{array}$ \\
\hline Nanoject@ & Debiotech, Switzerland & $\begin{array}{l}\text { Microneedle } \\
\text { array-based device }\end{array}$ & $\begin{array}{l}\text { Useful for intradermal and hypodermic drug delivery and for interstitial fluid } \\
\text { diagnostics }\end{array}$ \\
\hline Soluvia ${ }^{2}$ & Becton Dickinson, USA & $\begin{array}{l}\text { Hollow microneedle } \\
\text { array }\end{array}$ & $\begin{array}{l}\text { It is a prefillable microinjection system for accurate intradermal delivery of } \\
\text { drugs and vaccines. }\end{array}$ \\
\hline IDflu®/Intanza ${ }^{\circledR}$ & $\begin{array}{l}\text { Sanofi Pasteur, Lyon, } \\
\text { France }\end{array}$ & $\begin{array}{l}\text { Intradermal } \\
\text { microneedle } \\
\text { injection }\end{array}$ & Prefilled with influenza vaccine for intradermal influenza vaccination. \\
\hline Micronjet ${ }^{\circledR}$ & NanoPass Inc., Israel & $\begin{array}{l}\text { Intradermal } \\
\text { microneedle } \\
\text { injection }\end{array}$ & $\begin{array}{l}\text { It is used with any standard syringe for painless delivery of drugs, protein, } \\
\text { and vaccines. }\end{array}$ \\
\hline Macroflux® & $\begin{array}{l}\text { Zosano Pharma Inc., } \\
\text { USA }\end{array}$ & $\begin{array}{l}\text { Metallic microneedle } \\
\text { array }\end{array}$ & Delivery of peptides and vaccines \\
\hline Microcore $®$ & $\begin{array}{l}\text { Corium International } \\
\text { Inc., USA }\end{array}$ & $\begin{array}{l}\text { Dissolvable peptide } \\
\text { microneedle patch }\end{array}$ & $\begin{array}{l}\text { Deliver small as well as large molecules, like proteins, peptides, and } \\
\text { vaccines. }\end{array}$ \\
\hline Dermapen ${ }^{\circledR}$ & & $\begin{array}{l}\text { Microneedle } \\
\text { array-based device }\end{array}$ & $\begin{array}{l}\text { Used for treating various conditions of skin, ranging from acne, stretch mark, } \\
\text { and hair loss, and can enhance drug absorption. }\end{array}$ \\
\hline $\begin{array}{l}\text { Microstructured } \\
\text { transdermal patch }\end{array}$ & 3M Corp., USA & $\begin{array}{l}\text { Hollow microneedle } \\
\text { array }\end{array}$ & It delivers liquid formulations over a range of viscosities. \\
\hline
\end{tabular}

deposition was found to be $63.37 \%$, and transdermal flux was observed to be $1.60 \mu \mathrm{g} / \mathrm{cm}^{2} / \mathrm{h}$. Improvement in the skin permeation was found to be increased up to 2.58-folds as compared to that of the free drug solution [27]. Delivery of chemotherapeutic agents has also been successfully investigated. Bhatnagar et al. [28] investigated the delivery of chemotherapeutic agents, i.e., tamoxifen and gemcitabine, with the help of microneedles for the treatment of breast cancer. The localized delivery of these drugs helped reduce the side effects [28]. $\mathrm{Xu}$ et al. [29] reported a microneedle patch-mediated treatment of bacterial biofilms. They report a patch microneedle treatment for the successful removal of biofilms by penetrating the biofilm and delivering antibiotics directly to regions of active growth. They developed chloramphenicol (CAM)-bearing and gelatinasesensitive gelatin nanoparticle (CAM @ GNP)-filled patches with self-dissolving microneedles and needle tips. Finally, they concluded that for treatment of Vibrio vulnificus, biofilm microneedle-mediated treatment is more effective than the drug in free solution [29]. Neuropathic pain caused by nerve injury is difficult to treat because current systemic pharmacological therapies produce limited pain relief and have undesirable side effects, while current local anesthetics tend to nonspecifically block both sensory and motor functions. Xie et al. [30] developed analgesic microneedle patch (AMN) for neuropathic pain therapy, and they reported that AMN patches transdermally delivered calcitonin gene-related peptide (CGRP) antagonist peptide in a painless manner, producing effective and safe analgesia on neuropathic pain models, including spared nerve injury (SNI), diabetic neuropathy, and neurogenic inflammatory pain induced by UV radiation in rats [30]. It has also been used in combination with electroporation, iontophoresis, and other methods to give synergistic effects. Figure 2 shows various applications of microneedles. Additionally, $\mathrm{MN}$ research has been expanded from bench scale to pilot or industrial scale for societal benefits. MN-based clinical trials show a complete picture of the overall scenario and that can be seen in Table 2. As a next step, various MN-based pharmaceutical products with different therapeutic benefits are available in the market (Table 3). MNs have 


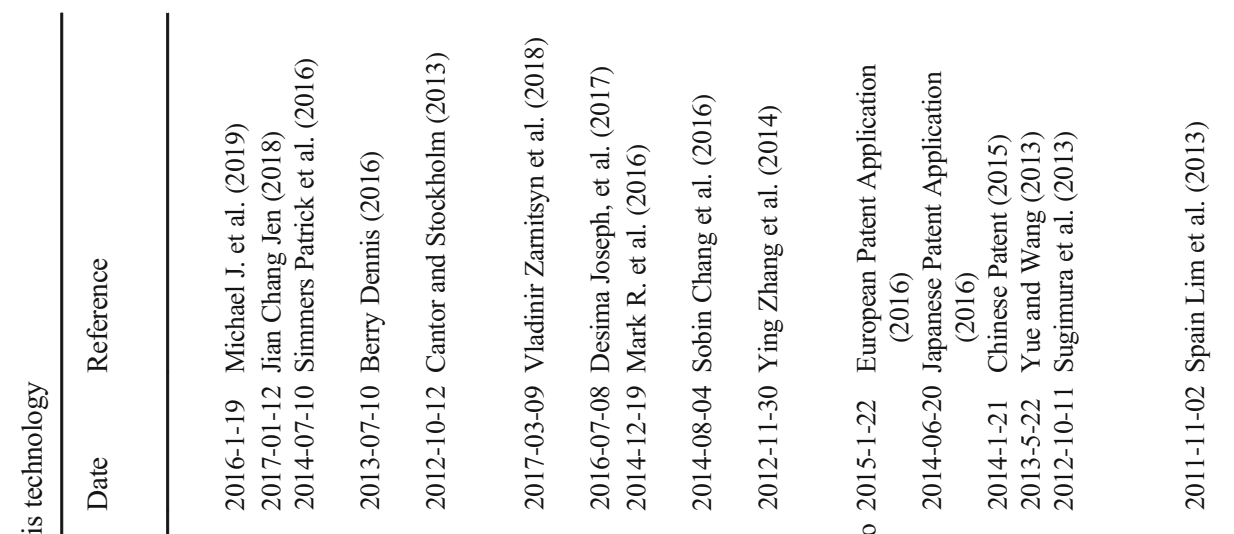

항

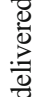

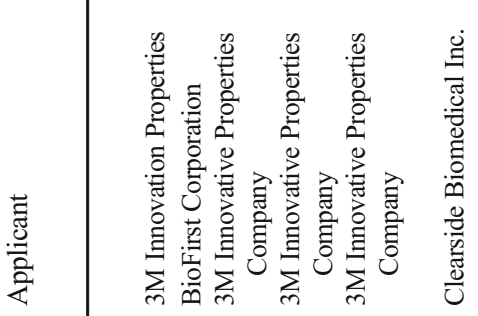

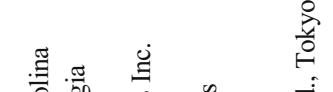

穿

:

콩

$\frac{0}{\bar{s}}$

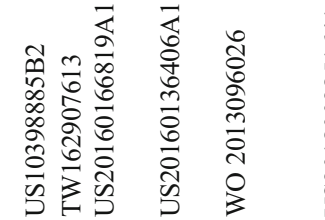

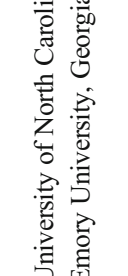

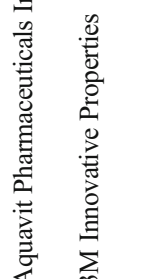

章

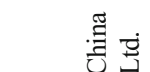

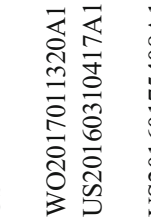

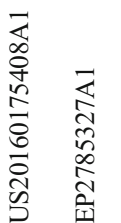

4

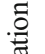

ํㅡㅇ

.

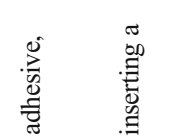

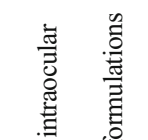

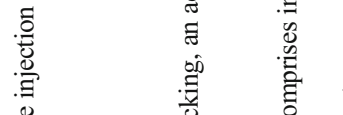


emerged as extra prominent within the past decade. The use of MNs as a way for the delivery of medication has to turn out to be a greater appealing method as it overcomes many disadvantages of hypodermic needles, transdermal patches, and other conventional dosage forms [31]. Therefore, it is essential to look at patents that have been filed within the last decade to correlate the trends of MNs. Table 4 depicts the list of some of the very useful patents that have been filled on microneedle technologies, therapeutically active molecules delivered by microneedle technology, and methods of MN fabrication technologies. All these empirical evidences show an encouraging trend in the development of MN-based technologies of therapeutic purposes.

\section{Conclusion and Future Prospect}

From the last 15 years, the deportment toward enhancing transdermal delivery of larger peptide, protein, and vaccine compound as well as traditional molecules has led to the MN-based product development and their regulation becoming the area of key importance to the researcher working in this area. Globally, the arrival of various commercial $\mathrm{MN}$ products is highly anticipated. MN may extend a remarkable impact on clinical medicine over the upcoming future.

Acknowledgment We are thankful to the Management and Director of the ISF College of Pharmacy, Moga, for providing necessary infrastructure and facilities to carry out this work. We are also thankful to $\mathrm{Mr}$. Manish Rai and Miss Pragati Rai for helping us out with technical and editorial improvements.

\section{Compliance with Ethical Standards}

Conflict of Interest None.

\section{References}

1. Rai VK, Mishra N, Agrawal AK, Jain S, Yadav NP. Novel drug delivery system: an immense hope for diabetics. Drug Deliv. 2016;23(7):2371-90.

2. Larrañeta E, Lutton REM, Woolfson AD, Donnelly RF. Microneedle arrays as transdermal and intradermal drug delivery systems: materials science, manufacture and commercial development. Mater Sci Eng R Rep. 2016;104:1-32.

3. Sivamani RK, Liepmann D, Maibach HI. Microneedles and transdermal applications. Expert Opin Drug Deliv. 2007;4(1):19-25.

4. Daddona PE, Matriano JA, Mandema J, Maa YF. Parathyroid hormone (1-34)-coated microneedle patch system: clinical pharmacokinetics and pharmacodynamics for treatment of osteoporosis. Pharm Res. 2011;28(1):159-65.

5. Arnou R, Icardi G, De Decker M, Ambrozaitis A, Kazek M-P, Weber $\mathrm{F}$, et al. Intradermal influenza vaccine for older adults: a randomized controlled multicenter phase III study. Vaccine. 2009;27(52):7304-12.

6. Rai VK, Mishra N, Yadav KS, Yadav NP. Nanoemulsion as pharmaceutical carrier for dermal and transdermal drug delivery: formulation development, stability issues, basic considerations and applications. J Control Release. 2018;270:203-25.

7. Yang J, Liu X, Fu Y, Song Y. Recent advances of microneedles for biomedical applications: drug delivery and beyond. Acta Pharm Sin B. 2019;9(3):469-83.

8. Donnelly RF, Raj Singh TR, Woolfson AD. Microneedle-based drug delivery systems: microfabrication, drug delivery, and safety. Drug Deliv. 2010;17(4):187-207.

9. Gerstel Martin S, Place Virgil A, Inventors; ALZA CORP, assignee. Drug delivery device. US patent US 3964482 A. 1976 1971/05/ 17.

10. Kim Y-C, Park J-H, Prausnitz MR. Microneedles for drug and vaccine delivery. Adv Drug Deliv Rev. 2012;64(14):1547-68.

11. Bora P, Kumar L, Bansal A. Microneedle technology for advanced drug delivery: evolving vistas. Curr Res Inf Pharm Sci. 2008;9.

12. Tuan-Mahmood TM, McCrudden MT, Torrisi BM, McAlister E, Garland MJ, Singh TR, et al. Microneedles for intradermal and transdermal drug delivery. Eur J Pharm Sci. 2013;50(5):623-37.

13. Ita K. Transdermal delivery of drugs with microneedles - potential and challenges. Pharmaceutics. 2015;7(3):90-105.

14. Rezaei Nejad H, Sadeqi A, Kiaee G, Sonkusale S. Low-cost and cleanroom-free fabrication of microneedles. Microsyst Nanoeng. 2018;4:17073.

15. Shewale J, Bhole K. 3D Polymer microneedle array: fabrication and analysis. 2015 International Conference on Nascent Technologies in the Engineering Field, ICNTE 2015-Proceedings. 2015.

16. Tabassum N, Sofi A, Khuroo T. Microneedle technology: a new drug delivery system. Int J Res Pharmaceut Biomed Sci. 2011;2: $59-62$.

17. Bariya SH, Gohel MC, Mehta TA, Sharma OP. Microneedles: an emerging transdermal drug delivery system. J Pharm Pharmacol. 2012;64(1):11-29.

18. Yang M, Zahn J. Microneedle insertion force reduction using vibratory actuation. Biomed Microdevices. 2004;6:177-82.

19. Waghule T, Singhvi G, Dubey SK, Pandey MM, Gupta G, Singh $\mathrm{M}$, et al. Microneedles: a smart approach and increasing potential for transdermal drug delivery system. Biomed Pharmacother. 2019;109:1249-58.

20. Wu Y, Qiu Y, Zhang S, Qin G, Gao Y. Microneedle-based drug delivery: studies on delivery parameters and biocompatibility. Biomed Microdevices. 2008;10:601-10.

21. Park JH, Allen MG, Prausnitz MR. Biodegradable polymer microneedles: fabrication, mechanics and transdermal drug delivery. J Control Release. 2005;104(1):51-66.

22. Ling MH, Chen MC. Dissolving polymer microneedle patches for rapid and efficient transdermal delivery of insulin to diabetic rats. Acta Biomater. 2013;9(11):8952-61.

23. Kommareddy S, Baudner BC, Bonificio A, Gallorini S, Palladino $\mathrm{G}$, Determan AS, et al. Influenza subunit vaccine coated microneedle patches elicit comparable immune responses to intramuscular injection in guinea pigs. Vaccine. 2013;31(34):3435-41.

24. Eun Kim GE, Huang S, Kenniston TW, Balmert SC, Carey CD. Microneedle array delivered recombinant coronavirus vaccines: immunogenicity and rapid translational development. Lancet. 2020;2020.

25. Patel SR, Lin AS, Edelhauser HF, Prausnitz MR. Suprachoroidal drug delivery to the back of the eye using hollow microneedles. Pharm Res. 2011;28(1):166-76.

26. Baek S-H, Shin J-H, Kim Y-C. Drug-coated microneedles for rapid and painless local anesthesia. Biomed Microdevices. 2017;19:2.

27. Amodwala S, Kumar P, Thakkar HP. Statistically optimized fast dissolving microneedle transdermal patch of meloxicam: a patient 
friendly approach to manage arthritis. Eur J Pharm Sci. 2017;104: 114-23.

28. Bhatnagar S, Kumari P, Pattarabhiran SP, Venuganti VVK. Zein microneedles for localized delivery of chemotherapeutic agents to treat breast cancer: drug loading, release behavior, and skin permeation studies. AAPS PharmSciTech. 2018;19(4):1818-26.

29. Xu J, Danehy R, Ao Z, Cai H, Pu M, Nusawardhana A, et al. Microneedle patch-mediated treatment of bacterial biofilms. ACS Appl Mater Interfaces. 2019;11.
30. Xie X, Pascual C, Lieu C, Oh S, Wang J, Zou B, et al. Analgesic microneedle patch for neuropathic pain therapy. 2017;11(1):395406.

31. He X, Sun J, Zhuang J, Xu H, Liu Y, Wu D. Microneedle system for transdermal drug and vaccine delivery: devices, safety, and prospects. Dose-Response. 2019;17(4):1559325819878585.

Publisher's Note Springer Nature remains neutral with regard to jurisdictional claims in published maps and institutional affiliations. 